\title{
Dependent Arising and the Emptiness of Emptiness: Why Did Nāgārjuna Start with Causation?
}

\section{Jay L. Garfield}

Smith College,jgarfield@smith.edu

Follow this and additional works at: https://scholarworks.smith.edu/phi_facpubs

Part of the Philosophy Commons

\section{Recommended Citation}

Garfield, Jay L., "Dependent Arising and the Emptiness of Emptiness: Why Did Nāgārjuna Start with Causation?" (1994). Philosophy: Faculty Publications, Smith College, Northampton, MA.

https://scholarworks.smith.edu/phi_facpubs/22 


\section{UNIVERSITY of \\ HAWAI'I \\ PRESS}

Dependent Arising and the Emptiness of Emptiness: Why Did Nāgārjuna Start with Causation?

Author(s): Jay L. Garfield

Source: Philosophy East and West, Vol. 44, No. 2 (Apr., 1994), pp. 219-250

Published by: University of Hawai'i Press

Stable URL: https://www.jstor.org/stable/1399593

Accessed: 03-08-2018 16:01 UTC

JSTOR is a not-for-profit service that helps scholars, researchers, and students discover, use, and build upon a wide range of content in a trusted digital archive. We use information technology and tools to increase productivity and facilitate new forms of scholarship. For more information about JSTOR, please contact support@jstor.org.

Your use of the JSTOR archive indicates your acceptance of the Terms \& Conditions of Use, available at https://about.jstor.org/terms

University of Hawai'i Press is collaborating with JSTOR to digitize, preserve and extend access to Philosophy East and West 
DEPENDENT ARISING AND THE EMPTINESS

OF EMPTINESS: WHY DID NĀGĀRJUNA

START WITH CAUSATION?

1. Introduction

Nāgārjuna, who lived in South India in approximately the first century C.E., is undoubtedly the most important, influential, and widely studied Mahāyāna Buddhist philosopher. He is the founder of the Mādhyamika, or Middle Path, schools of Mahāyāna Buddhism. His considerable corpus includes texts addressed to lay audiences, letters of advice to kings, and the set of penetrating metaphysical and epistemological treatises that represent the foundation of the highly skeptical and dialectical analytic philosophical school known as Mādhyamika. Most important of these is his largest and best-known text, the Mülamādhyamikakārikā-in English, Fundamental Stanzas on the Middle Way. This text in turn inspires a huge commentarial literature in Sanskrit, Tibetan, Chinese, Korean, and Japanese. Divergences in interpretation of the Mülamādhyamikakārikā often determine the splits between major philosophical schools. So, for instance, the distinction between two of the three major Mahāyāna philosophical schools, Svātantrika-Mādhyamika and Prāsangika-Mādhyamika, reflect, inter alia, distinct readings of this text, itself taken as fundamental by scholars within each of these schools.

The treatise itself is composed in very terse, often cryptic verses, with much of the explicit argument suppressed, generating significant interpretative challenges. But the uniformity of the philosophical methodology and the clarity of the central philosophical vision expressed in the text together provide a considerable fulcrum for exegesis. The central topic of the text is emptiness-the Buddhist technical term for the lack of independent existence, inherent existence, or essence in things. Nāgārjuna relentlessly analyzes phenomena or processes that appear to exist independently and argues that they cannot so exist, and yet, though lacking the inherent existence imputed to them either by naive common sense or by sophisticated, realistic philosophical theory, these phenomena are not nonexistent-they are, he argues, conventionally real.

This dual thesis of the conventional reality of phenomena together with their lack of inherent existence depends upon the complex doctrine of the two truths or two realities - a conventional or nominal truth and an ultimate truth-and upon a subtle and surprising doctrine regarding their relation. It is, in fact, this sophisticated development of the doctrine of the two truths as a vehicle for understanding Buddhist metaphysics and epistemology that is Nāgārjuna's greatest philosophical contribution. If the analysis in terms of emptiness is the substantial heart of Mülamādhyamikakārikā, the method of reductio ad absurdum is the methodolog-
Jay L. Garfieid

Professor of Philosophy

in the School of

Communications and

Cognitive Science at

Hampshire College
Philosophy East \& West

Volume 44, Number 2

April 1994

219-250

(c) 1994

by University of

Hawaii Press 
ical core. Nāgārjuna, like Western skeptics, systematically eschews the defense of positive metaphysical doctrines regarding the nature of things, demonstrating rather that any such positive thesis is incoherent, and that in the end our conventions and our conceptual framework can never be justified by demonstrating their correspondence to an independent reality. Rather, he suggests, what counts as real depends precisely upon our conventions. ${ }^{1}$

For Nāgārjuna and his followers, this point is connected deeply and directly with the emptiness of phenomena. That is, for instance, when a Madhyamika philosopher says of a table that it is empty, that assertion by itself is incomplete. It invites the question, "empty of what?" And the answer is: "empty of inherent existence, or self-nature, or, in more Western terms, essence." Now, to say that the table is empty is hence simply to say that it lacks essence and, importantly, not to say that it is completely nonexistent. To say that it lacks essence, the Madhyamika philosopher will explain, is to say, as the Tibetans like to put it, that it does not exist "from its own side" - that its existence as the object that it is, as a table, depends not only upon it or on any purely nonrelational characteristics, but upon us as well. That is, if this kind of furniture had not evolved in our culture, what appears to us to be an obviously unitary object might instead be correctly described as five objects: four quite useful sticks absurdly surmounted by a pointless slab of stick-wood waiting to be carved. It is also to say that the table depends for its existence on its parts, on its causes, on its material, and so forth. Apart from these, there is no table. The table, we might say, is a purely arbitrary slice of space-time chosen by us as the referent of a single name, and not an entity demanding, on its own, recognition and a philosophical analysis to reveal its essence. That independent character is precisely what it lacks, on this view.

And this analysis in terms of emptiness-an analysis refusing to characterize the nature of any thing, precisely because it denies that we can make sense of the idea of a thing's nature-proceeding by the relentless refutation of any attempt to provide such a positive analysis, is applied by Nāgārjuna to all phenomena, including, most radically, emptiness itself. For if Nāgārjuna merely argued that all phenomena are empty, one might justly indict him for in fact merely replacing one analysis of things with another; that is, with arguing that emptiness is in fact the essence of all things. But Nāgārjuna, as we shall see, argues that emptiness itself is empty. It is not a self-existent void standing behind the veil of illusion represented by conventional reality, but merely an aspect of conventional reality. And this, as we shall see, is what provides the key to understanding the deep unity between the two truths.

While Nāgārjuna is a powerfully original thinker, he is clearly and self-consciously operating squarely within the framework of Buddhist 
philosophy. Therefore, Nāgārjuna accepts, and takes it as incumbent upon him, to provide an account of the Four Noble Truths. Moreover, he takes it as a fundamental philosophical task to provide an understanding of what Buddhist philosophy refers to as pratityasammutpāda-dependent co-origination. This term denotes the nexus between phenomena in virtue of which events depend on other events, composites depend upon their parts, and so forth. Just how this dependency is spelled out, and just what is its status is a matter of considerable debate within Buddhist philosophy, just as the nature of causation and explanation is a matter of great dispute within Western philosophy. Nāgārjuna is very much concerned to stake out a radical and revealing position in this debate. I will argue that this position provides the key to understanding his entire text.

The Mülamādhyamikakārikā is divided into twenty-seven chapters. The first chapter addresses dependent origination. While many Western commentators assert that this chapter opens the text simply because it addresses a "fundamental doctrine of Buddhism" (Kalupahana 1986), I will argue that Nāgārjuna begins with causation for deeper, more systematic reasons. In chapters 2 through 23, Nāgārjuna addresses a wide range of phenomena, including external perceptibles, psychological processes, relations, and putative substances and attributes, arguing that all are empty. In the final four chapters, Nāgārjuna replies to objections and generalizes the particular analyses into a broad theory concerning the nature of emptiness itself and the relation between the two truths, emptiness and dependent arising itself. It is generally, and in my view correctly, acknowledged that chapter 24, the examination of the Four Noble Truths, is the central chapter of the text and the climax of the argument. One verse of this chapter, verse 18 , has received so much attention that interpretations of it alone represent the foundations of major Buddhist schools in East Asia:

Whatever is dependently co-arisen

That is explained to be emptiness.

That, being a dependent designation

Is itself the middle way.

Here Nāgārjuna asserts the fundamental identity of (1) emptiness, or the ultimate truth, (2) the dependently originated - that is, all phenomenaand (3) verbal convention. Moreover, he asserts that understanding this relation is itself the middle-way philosophical view he articulates in the Mülamädhyamikakārikā. This verse and the discussion in the chapters that follow provide the fulcrum for Candrakirti's more explicit characterization of the emptiness of emptiness as an interpretation of Nāgārjuna's philosophical system - the interpretation that is definitive of the PrāsangikaMādhyamika school. In what follows I will provide an interpretation of this central verse and its context that harmonizes with Candrakirti's and

Jay L. Garfield 
argue that, in fact, this doctrine is already to be found in the opening chapter of the text-the examination of conditions. Reading the text in this way, I will argue, locates the doctrine of the emptiness of emptiness not only as a dramatic philosophical conclusion to be drawn at the end of twenty-four chapters of argument, but as the perspective implicit in the argument from the very beginning, and only rendered explicit in chapter 24. Reading the text in this way, I will suggest, also shows us exactly how $24: 18$ is to be understood, and just why a proper understanding of causality is so central to Buddhist philosophy.

I will begin by offering a philosophical reading of chapter 1 . I will argue that Nāgārjuna distinguishes two possible views of dependent origination or the causal process-one according to which causes bring about their effects in virtue of causal powers and one according to which causal relations simply amount to explanatorily useful regularities-and defends the latter. This, I will argue, when suitably fleshed out, amounts to Nāgārjuna's doctrine of the emptiness of causation. I will then turn immediately to chapter 24, focusing on the link between emptiness, dependent origination, and convention, and developing the theory of the emptiness of emptiness. With this in hand, we will return to chapter 1, showing how this doctrine is anticipated in the initial discussion of causation. Finally, I will show quickly how this way of reading the texts changes the way we would read subsequent chapters, and I will make a few general remarks about the moral of this textual exercise for an understanding of the centrality of causation to metaphysics and for an understanding of the remarkably pragmatic outlook of Mādhyamika philosophy.

\section{Chapter 1-Examination of Conditions}

Central to this first chapter is the distinction between causes and conditions (Skt hetu and pratyaya [Tib rGyu and rKyen]. This distinction is variously drawn and is controversial, ${ }^{2}$ and is arguably differently understood in Sanskrit and Tibetan. The way I will understand it here, I argue, makes good, coherent sense not only of this chapter, but of the Mülamādhyamikakārikā as a whole. Briefly, we will understand this distinction as follows: When Nāgārjuna uses the word "cause" (hetu [rGyu]), he has in mind an event or state that has in it a power (kriyā [Bya Ba]) to bring about its effect, and has that power as part of its essence or nature (svabhāva [Rang bZhin]). When he uses the term "condition," on the other hand (pratyaya [rKyen]), he has in mind an event, state, or process that can be appealed to in explaining another event, state, or process, without any metaphysical commitment to any occult connection between explanandum and explanans. In chapter 1, Nāgārjuna, we shall see, argues against the existence of causes and for the existence of a variety of kinds of conditions. ${ }^{3}$ 
The argument against causation is tightly intertwined with the positive account of dependent arising and of the nature of the relation between conditions and the conditioned. Nāgārjuna begins by stating the conclusion (1:1): neither are entities self-caused nor do they come to be through the power of other entities. That is, there is no causation, when causation is thought of as involving causal activity. ${ }^{4}$ Nonetheless, he notes (1:2), there are conditions - in fact four distinct kinds - that can be appealed to in the explanation and prediction of phenomena. An example might be useful to illustrate the difference between the four kinds of condition, and the picture Nāgārjuna will paint of explanation. Suppose that you ask, "Why are the lights on?" I might reply as follows: (1) Because I flicked the switch. I have appealed to an efficient condition. Or (2) because the wires are in good working order, the bulbs haven't burned out, and the electricity is flowing. These are supporting conditions. Or (3) the light is the emission of photons each of which is emitted in response to the bombardment of an atom by an electron, and so forth. I have appealed to a chain of immediate conditions. Or (4) so that we can see. This is the dominant condition. Any of these would be a perfectly good answer to the "Why?" question. But note that none of them makes reference to any causal powers or necessitation.

The next three verses are crucial. Nāgārjuna first notes (1:3) that in examining a phenomenon and its relations to its conditions, we do not find that phenomenon somehow contained potentially in those conditions. Now, on the reading of this chapter, I will suggest, we can see conditions simply as useful explanans. Using this language, we can see Nāgārjuna as urging that even distinguishing clearly between explanans and explanandum as distinct entities, with the former containing potentially what the latter has actually, is problematic. What we are typically confronted with in nature is a vast network of interdependent and continuous processes, and carving out particular phenomena for explanation or for use in explanations depends more on our explanatory interests and language than on joints nature presents to us. Through addressing the question of the potential existence of an event in its conditions, Nāgārjuna hints at this concealed relation between praxis and reality.

Next, Nāgārjuna notes (1:4) that in exploiting an event or entity as a condition in explanation, we do not thereby ascribe it any causal power. Our desire for light does not exert some occult force on the lights. Nor is there anything to be found in the flicking of the switch other than the plastic, metal, movement, and connections visible to the naked eye. Occult causal powers are singularly absent. On the other hand, Nāgārjuna points out in the same breath that this does not mean that conditions are explanatorily impotent. In a perfectly ordinary sense-not that which the metaphysicians of causation have in mind-our desire is active in the

Jay L. Garfield 
production of light. But not in the sense that it contains light potentially, or some special causal power that connects our minds to the bulbs. ${ }^{5}$

What is it, then, about some sets of event pairs, but not others, that make them dependently related, if not some causal link present in some cases but not in others? Nāgārjuna replies (1:5) that it is the regularities that count. Flickings give rise to illuminations. So they are conditions of them. If they didn't, they wouldn't be. Period. Explanation relies on regularities. Regularities are explained by reference to further regularities. Adding active forces or potentials adds nothing of explanatory utility to the picture. ${ }^{6}$

In reading the next few verses we must be hermeneutically cautious, and pay careful attention to Nāgārjuna's use of the term "existent" (satah [Yod pa]) and its negative contrastive "nonexistent" (asatah [Med pa]). For Nāgārjuna is worried here about inherent existence and inherent nonexistence, as opposed to conventional existence or nonexistence. Though this will become clearer as we go along, keep in mind for the present that for a thing to exist inherently is for it to exist in virtue of possessing an essence; for it to exist independently of other entities, and independently of convention. For a thing to be inherently nonexistent is for it to not exist in any sense at all-not even conventionally or dependently.

With this in mind, we can see how Nāgārjuna defends dependent arising while rejecting causation. He notes (1:6) that if entities are conceived as inherently existent, they exist independently, and hence need no conditions for their production. Indeed, they could not be produced if they exist in this way. On the other hand, if things exist in no way whatsoever, it follows trivially that they have no conditions. This verse and the several that follow (1:6-10) make this point with regard to each of the four kinds of conditions.

What is important about this strand of the argument? Nāgārjuna is drawing attention to the connection between a causal-power view of causation and an essentialist view of phenomena on the one hand, and between a condition view of dependent arising and a conventional view of phenomena on the other. Here is the point: if one views phenomena as having and as emerging from casual powers, one views them as having essences and as being connected to the essences of other phenomena. This, Nāgārjuna suggests, is ultimately incoherent, since it forces one at the same time to assert the inherent existence of these things, in virtue of their essential identity, and to assert their dependence and productive character, in virtue of their causal history and power. But such dependence and relational character, he suggests, is incompatible with their inherent existence. If, on the other hand, one regards things as dependent merely on conditions, one regards them as merely conventionally existent. And to regard something as merely conventionally existent is to regard it as without essence and without power. And this is to regard it 
as existing dependently. This provides a coherent, mundane understanding of phenomena as an alternative to the metaphysics of reification that Nāgārjuna criticizes.

Verse 10 is central in this discussion.

If things did not exist

Without essence,

The phrase, "When this exists so this will be,"

Would not be acceptable.

Nāgārjuna is replying here to the causal realist's inference from the reality of causal powers to their embodiment in real entities whose essences include those powers. He turns the tables on the realist, arguing that it is precisely because there is no such reality to things - and hence no entities to serve as the bearers of the causal powers the realist wants to posit - that the Buddhist formula expressing the truth of dependent arising7 can be asserted. It could not be asserted if in fact there were real entities. For if they were real in the sense important for the realist, they would be independent. So if the formula were interpreted in this context as pointing to any causal power, it would be false. It can only be interpreted, it would follow, as a formula expressing the regularity of nature.

In the next three verses (1:11-13) Nāgārjuna anticipates and answers the causal realist's reply. First, the realist argues that the conclusion Nāgārjuna draws from the unreality of causal power-the nonexistence of things (where "existence" is read "inherent existence") - entails the falsity of the claim that things dependently arise (1:11). For if there are no things, surely nothing arises. This charge has a double edge: if the argument is successful it shows not only that Nāgārjuna's own position is vacuous, but also that it contradicts one of the most fundamental tenets of Buddhist philosophy: that all phenomena are dependently arisen. Moreover, the opponent charges (1:11), on Nāgārjuna's view that the explanandum is not to be found potentially in the explanans, there is no explanation of how the former is to be understood as depending upon the latter. As Nāgārjuna will emphasize, however (1:14), the very structure of this charge contains the seeds of its reply. The very emptiness of the effect, an effect presupposed by the opponent to be nonempty, in fact follows from the emptiness of the conditions and of the relationship between conditions and effect. Hence Nāgārjuna can reply to the opponents' attempted refutation by embracing the conclusion of his reductio together with the premises it supposedly refutes.

How, the opponent asks, are we to distinguish coincidental sequence from causal consequence? And why (1:12) don't things simply arise randomly from events that are nonconditions, since no special connection is posited to link consequents to their proper causal antecedents? Finally, the opponent asks (1:13), since the phenomena we observe clearly have

Jay L. Garfield 
natures, how could it be, as Nāgārjuna argues, that they proceed by means of a process with no essence, from conditions with no essence? Whence do the natures of actual existents arise? Nāgārjuna again replies to this last charge by pointing out that since on his view the effects indeed have no essence, the opponent's presupposition is ill-founded. This move also indicates a reply to the problem posed in (1:12); that problem is grounded in the mistaken view that a phenomenon's lack of inherent existence entails that it, being nonexistent, could come into existence from nowhere. But "from nowhere," for the opponent, means from something lacking inherent existence. And indeed, for Nāgārjuna, this is exactly the case: effects lacking inherent existence depend precisely upon conditions which themselves lack inherent existence.

Nāgārjuna's summary of the import of this set of replies (1:14) is terse and cryptic. But unpacking it with the aid of what has gone before provides an important key to understanding the doctrine of the emptiness of causation that is the burden of this chapter. First, Nāgārjuna points out, the opponent begs the question in asserting the genuine existence of the effects in question. They, like their conditions, and like the process of dependent origination itself, are nonexistent from the ultimate point of view. Hence the third charge fails. As a consequence, in the sense in which the opponent supposes that these effects proceed from their conditions - namely that their essence is contained potentially in their causes, which themselves exist inherently-these effects need not be so produced. And so, finally, the effect-containing conditions for which the opponent charges Nāgārjuna with being unable to account are themselves unnecessary. In short, while the reificationist critic charges the Mãdhyamika with failing to come up with a causal link sufficiently robust to link ultimately real phenomena, for the Mādhyamika philosopher, the core reason for the absence of such a causal link is the very absence of such phenomena in the first place.

We are now in a position to characterize explicitly the emptiness of causation, and the way this doctrine is identical with the doctrine of dependent origination from conditions adumbrated in this chapter. It is best to offer this characterization using the via media formulation most consonant with Nāgārjuna's philosophical school. We will locate the doctrine as a midpoint between two extreme philosophical views. That midpoint is achieved by taking conventions as the foundation of ontology, hence rejecting the very enterprise of a philosophical search for the ontological foundations of convention (Garfield 1990). To say that causation is nonempty or inherently existent is to succumb to the temptation to ground our explanatory practice and discourse in genuine causal powers linking causes to effects. That is the reificationist extreme which Nāgārjuna clearly rejects. To respond to the arguments against the inherent existence of causation by suggesting that there is then no possibility 
of appealing to conditions to explain phenomena-that there is no dependent origination at all-is the extreme of nihilism, also clearly rejected by Nāgārjuna. To assert the emptiness of causation is to accept the utility of our causal discourse and explanatory practice, but to resist the temptation to see these as grounded in reference to causal powers or as demanding such grounding. Dependent origination simply is the explicability and coherence of the universe. Its emptiness is the fact that there is no more to it than that.

Now this is certainly philosophically interesting stuff in its own right. But as I suggested at the outset, there is more to it than just an analysis of causation and dependent arising. For, as we shall see, for Nāgārjuna, among the most important means of demonstrating the emptiness of phenomena is to argue that they are dependently arisen. And so the claim that dependent arising itself is empty will turn out to be the claim that the emptiness of phenomena is itself empty-the central and deepest claim of Mādhyamika ontology.

\section{Chapter 24-Examination of the Four Noble Truths}

While Chapter 24 ostensibly concerns the Four Buddhist Truths and the way they are to be understood from the vantage point of emptiness, it is really about the nature of emptiness itself, and about the relation between emptiness and conventional reality. As such, it is the philosophical heart of the Mülamädhyamikakārikā. The first six verses of the chapter (24:1-6) present a reply to Nāgārjuna's doctrine of emptiness by an opponent charging the doctrine with nihilism. The next eight verses (24:7-14) are primarily rhetorical, castigating the opponent for his misunderstanding of Mādhyamika. The important philosophical work begins with 24: 15. From this point Nāgārjuna offers a theory of the relationship between emptiness, dependent origination, and convention, and argues not only that these three can be understood as co-relative, but that if conventional things (or emptiness itself) were nonempty, the very nihilism would ensue with which the reificationist opponent charges Mādhyamika. This tactic of arguing not only against each extreme but also that the contradictory extremes are in fact mutually entailing is a dialectical trademark of Nāgārjuna's philosophical method. Because of the length of this chapter, I will not provide a verse-by-verse reading here, but only a general gloss of the argument, with special attention to critical verses.

The opponent opens the chapter by claiming that if the entire phenomenal world were empty nothing would in fact exist, a conclusion absurd on its face and, more importantly, contradictory to fundamental Buddhist tenets such as the Four Noble Truths (24:1-6) as well as to conventional wisdom. The implicit dilemma with which Nāgārjuna confronts himself is elegant (24:6). For as we have seen, the distinction

Jay L. Garfield 
between the two truths, or two vantage points - the ultimate and the conventional-is fundamental to his own method. So when the opponent charges that the assertion of the nonexistence of such things as the Four Noble Truths and of the arising, abiding, and ceasing of entities is contradictory both to conventional wisdom and to the ultimate truth (namely, on one straightforward interpretation, that all phenomena are impermanent, that is, merely arising, abiding momentarily, and ceasing), Nāgārjuna is forced to defend himself on both fronts and to comment on the connection between these standpoints.

Nāgārjuna launches the reply by charging the opponent with foisting the opponent's own understanding of emptiness on Nāgārjuna. Though this is not made as explicit in the text as one might like, it is important to note that the understanding Nāgārjuna has in mind is one that, in the terms of Mādhyamika, reifies emptiness itself. Verse $24: 16$ provides a clue.

\author{
If the existence of all things \\ Is perceived in terms of their essence, \\ Then this perception of all things \\ Will be without the perception of causes and conditions.
}

The opponent is seeing actual existence as a discrete entity with an essence. It would follow that for the opponent, the reality of emptiness would entail that emptiness itself is an entity, and at that an inherently existing entity. To see emptiness in this way is to see it as radically different from conventional, phenomenal reality. It is to see the conventional as illusory and emptiness as the reality standing behind it. To adopt this view of emptiness is indeed to deny the reality of the entire phenomenal, conventional world. It is also to ascribe a special, nonconventional, nondependent hyperreality to emptiness itself. Ordinary things would be viewed as nonexistent, emptiness as substantially existent. (It is important and central to the Mādhyamika dialectic to see that these go togetherthat nihilism about one kind of entity is typically paired with reification of another.) This view is not uncommon in Buddhist philosophy, and Nāgārjuna is clearly aware that it might be suggested by his own position. So Nāgārjuna's reply must begin by distancing himself from this reified view of emptiness itself and hence from the dualism it entails. Only then can he show that to reify emptiness in this way would indeed entail the difficulties his imaginary opponent adumbrates, difficulties not attaching to Nāgārjuna's own view. This brings us to the central verses of this chapter (24: 18 and 24: 19):

Whatever is dependently co-arisen That is explained to be emptiness. That, being a dependent designation Is itself the middle way. 
Something that is not dependently arisen,

Such a thing does not exist.

Therefore a non-empty thing

Does not exist.

These verses demand careful scrutiny. In 24: 18, Nāgārjuna establishes a critical three-way relation between emptiness, dependent origination, and verbal convention, and asserts that this relation itself is the Middle Way towards which his entire philosophical system is aimed. As we shall see, this is the basis for understanding the emptiness of emptiness itself. First, Nāgārjuna asserts that the dependently arisen is emptiness. Emptiness and the phenomenal world are not two distinct things. They are rather two characterizations of the same thing. To say of something that it is dependently co-arisen is to say that it is empty. To say of something that it is empty is another way of saying that it arises dependently.

Moreover, whatever is dependently co-arisen is verbally established. That is, the identity of any dependently arisen thing depends upon verbal conventions. To say of a thing that it is dependently arisen is to say that its identity as a single entity is nothing more than its being the referent of a word. The thing itself, apart from conventions of individuation, is nothing but an arbitrary slice of an indefinite spatiotemporal and causal manifold. To say of a thing that its identity is a merely verbal fact about it is to say that it is empty. To view emptiness in this way is to see it neither as an entity nor as unreal-it is to see it as conventionally real. Moreover, "emptiness" itself is asserted to be a dependent designation (Skt prajñaptir-upadaya [brTen Nas gDags pa]). Its referent, emptiness itself, is thereby asserted to be merely dependent and nominal-conventionally existent but ultimately empty. This is, hence, a middle path with regard to emptiness. To view the dependently originated world in this way is to see it neither as nonempty nor as completely nonexistent. It is, viewed in this way, conventionally existent, but empty. We thus have a middle path with regard to dependent origination. To view convention in this way is to view it neither as ontologically insignificant-it determines the character of the phenomenal world-nor as ontologically efficacious - it is empty. Thus we also have a middle way with regard to convention. And finally, given the nice ambiguity in the reference of "that," (De Ni), not only are "dependent arising" and "emptiness" asserted to be dependent designations, and hence merely nominal, but the very relation between them is asserted to be so dependent, and therefore to be empty. ${ }^{8}$

These morals are driven home in 24:19, where Nāgārjuna emphasizes that everything - and this must include emptiness - is dependently arisen. So everything-including emptiness-lacks inherent existence.

Jay L. Garfield 
So nothing lacks the three coextensive properties of emptiness, dependentorigination, and conventional identity.

With this in hand, Nāgārjuna can reply to the critic. He first points out (24:20-35) that in virtue of the identity of dependent origination and emptiness on the one hand and of ontological independence and intrinsic reality on the other, such phenomena as arising, ceasing, suffering, change, enlightenment, and so on-the very phenomena the opponent charges Nāgārjuna with denying - are possible only if they are empty. The tables are thus turned: it appears that Nāgārjuna, in virtue of arguing for the emptiness of these phenomena, was arguing that in reality they do not exist, precisely because, for the reifier of emptiness, existence and emptiness are opposites. But in fact, because of the identity of emptiness and conventional existence, it is the reifier who, in virtue of denying the emptiness of these phenomena, denies their existence. And it is hence the reifier of emptiness who is impaled on both horns of the dilemma s/he has presented to Nāgārjuna: contradicting the ultimate truth, $s /$ he denies that these phenomena are empty; contradicting the conventional, $s / h e$ is forced to deny that they even exist! And so Nāgārjuna can conclude (24: 36):

If dependent arising is denied,
Emptiness itself is rejected.
This would contradict
All of the worldly conventions.

To assert the nonemptiness of phenomena and of their interrelations, Nāgārjuna suggests, when emptiness is properly understood, is not only philosophically deeply confused, it is contradictory to common sense. We can make sense of this argument in the following way: common sense neither posits nor requires intrinsic reality in phenomena or a real causal nexus; common sense holds the world to be a network of dependently arisen phenomena. So common sense holds the world to be empty. Again, the standpoint of emptiness is not at odds with the conventional standpoint, only with a particular philosophical understanding of it - that which takes the conventional to be more than merely conventional. What is curious - and, from the Buddhist standpoint, sadabout the human condition, on this view, is the naturalness and seductiveness of that philosophical perspective. ${ }^{9}$

\section{The Emptiness of Emptiness}

Let us consider now what it is to say that emptiness itself is empty. The claim, even in the context of Buddhist philosophy, does have a somewhat paradoxical air. For emptiness is, in Mahāyāna philosophical thought, the ultimate nature of all phenomena. And the distinction between the merely conventional nature of things and their ultimate nature 
While it is plausible to say that what is merely apparent is empty of reality, it seems nihilistic to say that what is ultimately real is empty of reality, and, as we have seen, the Mādhyamika are quite consciously antinihilistic. But again, when we say that a phenomenon is empty, we say, inter alia, that it is impermanent, that it depends upon conditions, and that its identity is dependent upon convention. Do we really want to say of each phenomenon that its emptiness - the fact that it is empty-is itself impermanent, itself dependent on something else, itself dependent upon conventions? It might at least appear that even if all other properties of conventional entities were so, their emptiness would be an eternal, independent, essential fact.

It may be useful to approach the emptiness of emptiness by first asking what it would be to treat emptiness as nonempty. When we say that a phenomenon is empty, we mean that when we try to specify its essence, we come up with nothing. When we look for the substance that underlies the properties, or the bearer of the parts, we find none. When we ask what it is that gives a thing its identity, we stumble not upon ontological facts but upon conventions. For a thing to be nonempty would be for it to have an essence discoverable upon analysis; for it to be a substance independent of its attributes, or a bearer of parts; for its identity to be self-determined by its essence. A nonempty entity can be fully characterized nonrelationally.

For emptiness to be nonempty would be for it to be a substantial entity, an independent existent, a nonconventional phenomenon. On such a view, arguably held by certain Buddhist philosophical schools, emptiness is entirely distinct from any conventional phenomenon. It is, on such a view, the object of correct perception, while conventional phenomena are the objects of delusive perception. While conventional phenomena are dependent upon conventions, conditions, or the ignorance of obstructed minds, emptiness, on such a view, is apparent precisely when one sees through those conventions, dispels that ignorance, and overcomes those obstructions. It has no parts or conditions, and no properties. Though such a position might appear metaphysically extravagant, it is hardly unmotivated. For one thing, it seems that emptiness does have an identifiable essence-namely the lack of inherent existence. So if to be empty is to be empty of essence, emptiness fails on that count to be empty. Moreover, since all phenomena, on the Mādhyamika view, are empty, emptiness would appear to be eternal and independent of any particular conventions, and hence not dependently arisen. The Two Truths, on such an ontological vision, are indeed radically distinct from one another.

But this position is, from Nāgārjuna's perspective, untenable. The best way to see that is as follows. Suppose that we take a conventional entity, such as a table. We analyze it to demonstrate its emptiness, finding that 
there is no table apart from its parts, that it cannot be distinguished in a principled way from its antecedent and subsequent histories, and so forth. So we conclude that it is empty. But now let us analyze that emptiness - the emptiness of the table - to see what we find. What do we find? Nothing at all but the table's lack of inherent existence. The emptiness is dependent upon the table. No conventional table-no emptiness of the table. To see the table as empty, for Nāgārjuna, is not to somehow see "beyond" the illusion of the table to some other, more real entity. It is to see the table as conventional, as dependent. But the table that we so see when we see its emptiness is the very same table, seen not as the substantial thing we instinctively posit, but rather as it is. Emptiness is hence not different from conventional reality - it is the fact that conventional reality is conventional. Therefore it must be dependently arisen, since it depends upon the existence of empty phenomena. Hence emptiness itself is empty. This is perhaps the deepest and most radical step in the Madhyamika dialectic, but it is also, as we shall see, the step that saves it from falling into metaphysical extravagance and brings it back to sober, pragmatic skepticism.

Now, this doctrine of the emptiness of emptiness emerges directly from 24: 18.
Whatever is dependently co-arisen
That is explained to be emptiness.
That, being a dependent designation
Is itself the middle way.

For the emptiness of emptiness, as we have just seen, simply amounts to the identification of emptiness with the property of being dependently arisen, and with the property of having an identity just in virtue of conventional, verbal designation. It is the fact that emptiness is no more than this that makes it empty, just as it is the fact that conventional phenomena in general are no more than conventional, and no more than their parts and status in the causal nexus that makes them empty. ${ }^{10}$

So the doctrine of the emptiness of emptiness can be seen as inextricably linked with Nāgārjuna's distinctive account of the relation between the two truths. For Nāgārjuna, as is also evident in this crucial verse, it is a mistake to distinguish conventional from ultimate reality - the dependently arisen from emptiness - at an ontological level. Emptiness just is the emptiness of conventional phenomena. To perceive conventional phenomena as empty is just to see them as conventional, and as dependently arisen. The difference - such as it is - between the conventional and the ultimate is a difference in the way phenomena are conceived/ perceived. The point must be formulated with some delicacy, and cannot be formulated without a hint of the paradoxical about it: conventional phenomena are typically represented as inherently existent. We typically 
perceive and conceive of external phenomena, ourselves, causal powers, moral truths, and so forth as independently existing, intrinsically identifiable and substantial. But though this is, in one sense, the conventional character of conventional phenomena-the manner in which they are ordinarily experienced - to see them this way is precisely not to see them as conventional. To see that they are merely conventional, in the sense adumbrated above and defended by Nāgārjuna and his followers, is thereby to see them as empty, and this is their ultimate mode of existence. These are the two truths about phenomena: On the one hand they are conventionally existent and the things we ordinarily say about them are in fact true, to the extent that we get it right on the terms of the everyday. Snow is indeed white, and there are indeed tables and chairs in this room. On the other hand, they are ultimately nonexistent. These two truths seem as different as night and day-being and nonbeing. But the import of 24:18 and the doctrine we have been explicating is that their ultimate nonexistence and their conventional existence are the same thing. Hence the deep identity of the two truths. And this is because emptiness is not other than dependent-arising, and hence because emptiness is empty.

Finally, in order to see why chapter 1 is not only an essential groundwork for this central argument, but in fact anticipates it and brings its conclusion to bear implicitly on the whole remainder of the text, we must note that this entire account depends upon the emptiness of dependent origination itself. To see this, suppose for a moment that one had the view that dependent arising were nonempty (not a crazy view, and not obviously incompatible with, and arguably entailed by, certain Buddhist doctrines). Then from the identification of emptiness with dependent arising would follow the nonemptiness of emptiness. Moreover, if conventional phenomena are empty, and dependent arising itself is nonempty and is identified with emptiness, then the two truths are indeed two in every sense. Emptiness-dependent arising is self-existent, while ordinary phenomena are not, and one gets a strongly dualistic, ontological version of an appearance-reality distinction. So the argument for the emptiness of emptiness in chapter 24 and the identity of the Two Truths with which it is bound up depend critically on the argument for the emptiness of dependent origination developed in chapter 1.

\section{Simple Emptiness versus the Emptiness of Emptiness}

We can now see why real causation, in the fully reified cement-ofthe-universe sense, as the instantiation of the relation between explanans and explananda could never do from the Mãdhyamika standpoint. For though that would at first glance leave phenomena themselves empty of inherent existence, it would retain a nonempty feature of the phenomenal world, and lose the emptiness of emptiness itself. Moreover, a bit of

Jay L. Garfield 
reflection should lead us to recognize the deep tension in this metaphysics: if the causal powers of things are ultimately real, it is hard to see how one could maintain the merely conventional status of the things themselves. For they could always be individuated as the bearers of those ultimately real causal powers, and the entire doctrine of the emptiness of phenomena would collapse.

Substituting conditions for causes solves this problem. For, as we have seen, by shifting the account in this way we come to understand the relation between conditions and the conditioned as obtaining in virtue of regularity and explanatory utility. And both of these determinants of the relation are firmly rooted in convention rather than in any extraconventional facts. Regularity is always regularity-under-adescription, and descriptions are, as Nāgārjuna puts it, "verbal designations." Explanatory utility is always relative to human purposes and theoretical frameworks. Dependent origination is thus on this model a thoroughly conventional and hence empty alternative to a reified causal model, which nonetheless permits all of the explanatory moves that a theory committed to causation can make. For every causal link one might posit, an equivalent conditional relation can be posited. But the otiose and ultimately incoherent posit of causal power is dispensed with on Nāgārjuna's formulation.

But if the foregoing interpretation is correct, we can make a more radical interpretative claim regarding the structure of Mülamãdhyamikakārikā: the entire doctrine of the emptiness of emptiness and the unity of the Two Truths developed in chapter 24 is already implicit in chapter 1. Recall the structure of the argument so far, as we have traced the complex doctrinal web Nāgārjuna spins: the central thesis of chapter 1 as we have characterized it is that there is no inherently existent causal nexus. The link between conditions and the phenomena dependent upon them is empty. To be empty is, however, to be dependent. Emptiness itself is, therefore, as is explicitly articulated in chapter 24, dependent arising. Hence the emptiness of dependent arising is the emptiness of emptiness. And the emptiness of emptiness, as we have seen, is equivalent to the deep identity between the Two Truths. So the entire central doctrine developed in the climactic twenty-fourth chapter is present in embryo in the first. And this is why Nāgārjuna began with causation.

Now, to be sure, it is not apparent on first reading the opening chapter of the Mülamādhyamikakārikā that this is the import of the argument. The rhetorical structure of the text only makes this clear in retrospect, when enough of the philosophical apparatus is on the table to make the entire framework clear. But once we see this framework, a rereading of the text in light of this understanding of the opening chapter is instructive. For it is one thing to argue for the emptiness of some phenomenon simpliciter and quite another to argue for that emptiness 
with the emptiness of emptiness in mind. If we read the opening chapter in the first way, we are likely to miss the force of many of the particular analyses in the text the depth of which only emerges in light of the deeper thesis of the emptiness of emptiness. If one argues simply that a phenomenon is empty of inherent existence, one leaves open the possibility that this is in contrast to phenomena that are inherently existent, and hence that the force of this argument is that the phenomenon in question is not actually existent. If, on the other hand, one argues that a phenomenon is empty in the context of the emptiness of emptiness, one is explicitly committed to the view that its emptiness does not entail its nonactuality. Emptiness in this context is not nonexistence. The lack of inherent existence that is asserted is not the lack of a property possessed by some entities but not by others, or a property that an entity could be imagined to have, but rather the lack of an impossible attribute. This reorientation of the argument gives what might appear to be a series of starkly nihilistic analyses a remarkably positive tone.

We have time here to consider briefly one example of the difference that this reading of chapter 1 induces in reading the subsequent text. We will consider the analysis of motion and rest in chapter 2 . I will not provide a verse-by-verse commentary on the chapter here. But let us note the following salient features of Nāgārjuna's analysis: the target of the argument is a view of motion according to which motion is an entity, or at least a property with an existence independent of that of moving things, or according to which motion is part of the nature of moving things. These are versions of what it would be to think of motion as nonempty. Nāgārjuna argues that from such a view a number of absurd consequences would follow: things not in motion but which were in motion in the past or which will be in the future would have to undergo substantial change, effectively becoming different things when they changed state from motion to rest or vice versa; a regress would ensue from the need for the entity motion itself to be in motion; motion would occur in the absence of moving things; the moment at which a thing begins or ceases motion would be indescribable. Nāgārjuna concludes that a reification of motion is incoherent. Motion is therefore empty.

So far so good. But then, is motion nonexistent? Is the entire universe static according to Mādhyamika philosophy? If we simply read this chapter in isolation, that conclusion might indeed seem warranted. It would be hard to distinguish emptiness from complete nonexistence. We would be left with an illusory world of change and movement, behind which would lie a static ultimate reality. But such a reading would be problematic. For one thing, it would be absurd on its face. Things move and change. Second, it would contradict the doctrine of dependent origination and change that is the very basis of any Buddhist philosophical system, and which Nāgārjuna has already endorsed in the opening chap-

Jay L. Garfield 
ter. How, then, are we to read this discussion more positively? Answering this question is hermeneutically critical not only for an understanding of this chapter, but - take my word for it - for a reading of the entire text, which, if not read with care, can appear unrelentingly nihilistic. And on such a nihilistic reading, the appearance/reality distinction that is forced can only coincide with the conventional reality/emptiness distinction, resulting in a denial of reality to the mundane world and a reification of emptiness itself.

The positive account we are after emerges when we recall the emptiness of emptiness and read this second chapter in the context of the reinterpreted first chapter: emptiness itself, as we have seen, according to the analysis of dependent arising, is dependently arisen. It is nothing but the emptiness of conventional phenomena, and is the fact of their being dependent and conventional. If emptiness itself is understood as nonempty, on the other hand, then for a phenomenon to be denominated empty is for it to be completely nonexistent. For then its merely conventional character would stand against the ultimate reality of emptiness itself. We have just seen how this would play out in the case of motion, and a moment's reflection would indicate that any other phenomenon subjected to this analysis would fare about as well. But consider, on the other hand, how we interpret the status of motion in light of the emptiness of its emptiness: the conclusion that motion is empty is then simply the conclusion that it is merely conventional and dependent, like the putatively moving entities themselves. Since there is no implicit contrastive, inherently existent ultimate reality, this conclusion does not lead us to ascribe a "second class" or merely apparent existence to motion or to movers. Their nonexistence-their emptiness-is hence itself non-existent in exactly the sense that they are. Existence-of a sort - is thus recovered exactly in the context of an absence of inherent existence.

But existence of what kind? Herein lies the clue to the positive construction of motion that emerges. The existence that emerges is a conventional and dependent existence. Motion does not exist as an entity on this account, but rather as a relation-as the relation between the positions of a body at distinct times, and hence is dependent upon that body and those positions. Moreover, it emerges as a conventional entity in the following critical sense: only to the extent that we make the decision to identify entities that differ from each other in position over time, but are in other respects quite similar, and which form causal chains of a particular sort, as the same entity can we say that the entity so identified moves. And this is a matter of choice. For we could decide to say that entities that differ in any respect are thereby distinct. If we did adopt that convention for individuation, an entity here now and one there then would ipso facto be distinct entities. And so no single entity 
could adopt different positions (or different properties) at different times, and so motion and change would be nonexistent. It is this dependence of motion on the moved, of the status of things as moved on their motion, and of both on conventions of individuation that, on this account, constitutes their emptiness. But this simply constitutes their conventional existence, and provides an analysis of the means by which they so exist. The emptiness of motion is thus seen to be its existence as conventional and as dependent and hence as not other than its conventional existence. And this just is the emptiness of emptiness. But in understanding its emptiness in this way, we bring motion, change, and movable and changeable entities back from the brink of extinction.

It is thus that seeing Nāgārjuna's analysis of the emptiness of phenomena in the context of the emptiness of emptiness allows for a nonnihilistic, nondualistic, constructive reading of the Mādhyamika dialectic, but a reading which for all of that is rich in its explication of the structure of reality and of our relation to it. But this reading is only accessible in the chapters analyzing particular phenomena if we already find it in chapter 1. And this, I have argued, is possible once we reread that initial chapter in light of the analysis in chapter 24 . The Nāgārjuna who emerges is a subtle figure indeed.

\section{The Importance of Causation}

The analysis of causation can often look like a highly technical aside in philosophy. It might not seem at first glance to be one of the really "big" questions, like those concerning what entities there are, what the nature of mind is, what the highest good is. By contrast, causation often appears to the outsider or to the beginner like one of those recherché corners of philosophy that one has to work one's way into. But of course even in the history of Western metaphysics and epistemology it has always been central. One has only to think of the role of a theory of causation for Hume, Kant, Schopenhauer, or Wittgenstein to see this. This study of the Mülamādhyamikakārikā shows why: a clear understanding of the nature of the causal relation is the key to understanding the nature of reality itself and of our relation to it. For causation is, as Hume, Kant, and Schopenhauer as well as Nāgārjuna emphasize, at the heart of our individuation of objects, of our ordering of our experience of the world, and of our understanding of our own agency in the world. Without a clear view of causation, we can have no clear view of anything.

Nāgārjuna begins by examining the causal relation for this reason generally. But for Nāgārjuna there is a further, more specific reason, one which has no explicit parallel in the work of other systematic philosophers, though it is, to be sure, hinted at darkly in the work of those just mentioned. For Nāgārjuna, by examining the nature of dependent arising, and by showing the emptiness of causation itself, we understand the

Jay L. Garfield 
nature of emptiness itself, and thereby push the Mādhyamika dialectic of emptiness to its conclusion. By showing causation to be empty, we show all things to be empty, even emptiness itself. Nāgārjuna begins here because, by beginning with causation, the important conclusions he drives at are ready at hand throughout the examination, even if they are not made explicit until much later.

\section{Antimetaphysical Pragmatism in Buddhism}

When a Westerner first encounters the Mülamädhyamikakārikā or other Mādhyamika texts, the philosophical approach can appear highly metaphysical and downright weird. The unfamiliar philosophical vocabulary, the highly negative dialectic, and the cryptic verse form are indeed forbidding. Most bizarre of all, however, at first glance, is the doctrine that all phenomena, including self and its objects, are empty. For indeed Nāgārjuna and his followers do argue that the entire everyday world is, from the ultimate standpoint, nonexistent. And that does indeed appear to stand just a bit deeper into philosophical left field than even Berkeley dares to play. But if the interpretation I have been urging is adopted, the real central thrust of Mādhyamika is the demystification of this apparently mystical conclusion. While it might appear that the Mādhyamika argue that nothing really exists except a formless, luminous void, in fact the entire phenomenal world, persons and all, are recovered within that emptiness.

And if what I have said is correct, the principal philosophical move in this demystification of emptiness is the attack on a reified view of causality. Nāgārjuna replaces the view shared by the metaphysician and the person-in-the-street - a view that presents itself as common sense, but is in fact deeply metaphysical - with an apparently paradoxical, thoroughly empty, but in the end actually commonsense view not only of causation, but of the entire phenomenal world.

\section{APPENDIX: TRANSLATION OF CHAPTERS 1, 2, AND 24 OF THE MÜLAM $\bar{A} D H Y A M I K A K \bar{A} R I K \bar{A}$ (TRANSLATED FROM THE TIBETAN TEXT)}

\section{Chapter 1-Examination of Conditions}

1. Neither from itself nor from another Nor from both, Nor from a non-cause Does anything whatever, anywhere arise. 
2. There are four conditions: efficient condition; Percept-object condition; immediate condition; Dominant condition, just so. There is no fifth condition.

3. The essence of entities is not evident in the conditions, and so forth. If these things are selfless, There can be no otherness-essence.

4. Power to act does not have conditions,

There is no power to act without conditions.

There are no conditions without power to act. Nor do any have the power to act.

5. These give rise to those, So these are called conditions.

As long as those do not come from these, Why are these not non-conditions?

6. For neither an existent nor a nonexistent thing Is a condition appropriate.

If a thing is nonexistent, how could it have a condition?

If a thing is already existent, what would a condition do?

7. Neither existents nor

Nonexistents nor existent nonexistents are produced.

In this case, how would there be a "productive cause?"

If it existed, how would it be appropriate?

8. Certainly, an existent mental episode

Has no object.

Since a mental episode is without an object,

How could there be any percept-condition?

9. Since things are not arisen,

It is not acceptable that they cease.

Therefore, an immediate condition is not reasonable.

If something has ceased, how could it be a condition?

10. If things did not exist

Without essence,

The phrase, "When this exists so this will be,"

Would not be acceptable.

11. In the various conditions united,

The effect cannot be found.

Nor in the conditions themselves.

So how could it come from the conditions?

12. However, if a nonexistent effect

Arises from these conditions,

Why does it not arise

From non-conditions?

Jay L. Garfield 
13. If the effect is the conditions' essence,

Then the conditions do not have their own essence.

So, how could an effect come

From something that is essenceless?

14. Therefore, conditions have no essence.

If conditions have no essence, there are no effects.

If there are no effects without conditions,

How will conditions be evident?

\section{Chapter 2-Examination of Motion}

1. What has been moved is not moving.

What has not been moved is not moving.

Apart from what has been moved and what has not been moved,

Movement cannot be conceived.

2. Where there is flux, there is motion.

Since there is flux in the moving,

And not in the moved or not-moved,

Motion is in that which is moving.

3. If motion is in the mover,

Then how would it be acceptable

When it is not moving,

To have called it a mover?

4. The motion of what moves?

What motion does not move?

Given that that which has passed is gone,

How can motion be in the moved?

5. If motion is in the mover,

There would have to be a twofold motion:

One in virtue of which it is a mover,

And one in virtue of which it moves.

6. If there were a twofold motion,

The subject of that motion would be twofold.

For without a subject of motion,

There cannot be motion.

7. If there is no mover

It would not be correct to say that there is motion.

If there is no motion,

How could a mover exist?

8. Inasmuch as a real mover does not move,

And a nonmover does not move,

Apart from a mover and a nonmover,

Philosophy East \& West

What third thing could move? 
9. When without motion,

It is unacceptable to call something a mover,

How will it be acceptable

To say that a moving thing moves?

10. For him from whose perspective a mover moves,

There is no motion.

If a real mover were associated with motion,

A mover would need motion.

11. If a mover were to move,

There would be a twofold motion:

One in virtue of which he is a mover,

And one in virtue of which the mover moves.

12. Motion does not begin in what has moved,

Nor does it begin in what has not moved,

Nor does it begin in what is moving.

In what, then, does motion begin?

13. If motion was begun in the past,

When should we say it began?

Not in the nongoing, not in the gone.

How could it be in the nonmoved?

14. Since the beginning of motion

Cannot be conceived,

What gone thing, what going thing,

And what nongoing thing can be conceived?

15. A moving thing is not at rest.

A nonmoving thing is not at rest.

Apart from the moving and the nonmoving,

What third thing is at rest?

16. If without motion

It is not appropriate to posit a mover,

How could it be appropriate to say

That a moving thing is stationary?

17. One does not halt from moving,

Nor from having moved or not having moved.

Motion and coming to rest

And starting to move are similar.

18. That motion is the mover

Itself is not correct.

Nor is it correct that

They are different.

19. It would follow from

The identity of mover and motion

That agent and action

Are identical.

Jay L. Garfield 
20. It would follow from

A real distinction between motion and mover That there could be a mover without motion And motion without a mover.

21. When neither in identity

Nor in difference,

Can motion and the mover be established as existent,

How can they be established as entities at all?

22. The motion by means of which a mover is manifest Cannot be the motion by means of which he moves.

He does not exist before that motion,

So what and where is the thing that moves?

23. A mover does not carry out a different motion

From that by means of which he is manifest as a mover.

Moreover, in one mover

A twofold motion is unacceptable.

24. A really existent mover

Does not move in any of the three ways.

A nonexistent mover

Does not move in any of the three ways.

25. Neither an entity nor a nonentity

Moves in any of the three ways.

So movement and motion

And Agent of motion are nonexistent.

\section{Chapter 24-Examination of the Four Noble Truths}

1. If all of this is empty,

Not arising, abiding, or ceasing,

Then for you, it follows that

The Four Noble Truths do not exist.

2. If the Four Noble Truths do not exist, Then knowledge, abandonment, Meditation, manifestation, and action

Will be completely impossible.

3. If these things do not exist,

The four fruits will not arise.

Then there will not be the enterers into the path.

If not, there will not be the eight [kinds of practitioner].

4. If so the assembly of holy ones

Itself will not exist.

If the Four Noble Truths do not exist,

Philosophy East \& West There will be no true Dharma. 
5. If there is no doctrine and assembly

How can there be a Buddha?

If emptiness is conceived in this way

The Three Jewels are contradicted.

6. The attainment of the real fruits

And the Dharma will not exist, and the Dharma itself

And the conventional truth

Will be contradicted.

7. This understanding of yours

Of emptiness and the purpose of emptiness

And of the significance of emptiness is incorrect.

As a consequence you are harmed by it.

8. The Buddha's teaching of the Dharma

Is based on two truths:

A truth of worldly convention

And an ultimate truth.

9. Those who do not understand

The distinction drawn between these two truths

Do not understand

The Buddha's profound truth.

10. Without a foundation in the conventional truth

The significance of the ultimate cannot be taught.

Without understanding the significance of the ultimate,

Liberation is not achieved.

11. By a misperception of emptiness

A person of little intelligence is destroyed.

Like a snake incorrectly seized

Or like a spell incorrectly cast.

12. For that reason-that the Dharma is

Deep and difficult to understand and to learn-

That (the Buddha's) mind despaired of

Being able to teach it.

13. If a fault in understanding should arise

with regard to emptiness, that would not be good.

Your confusion about emptiness, however,

Would not belong to me.

14. For him to whom emptiness is clear,

Everything becomes clear.

For him for whom emptiness is not clear,

Nothing becomes clear.

15. If you foist on us

All of your divergent views

Then you are like a man who has mounted his horse

And has forgotten that very horse.

Jay L. Garfield 
16. If the existence of all things

Is perceived by you in terms of their essence,

Then this perception of all things

Will be without the perception of causes and conditions.

17. Effects and causes

And agent and action

And conditions and arising and ceasing

And effects will be rendered impossible.

18. Whatever is dependently co-arisen

That is explained to be emptiness.

That, being a dependent designation

Is itself the middle way.

19. Something that is not dependently arisen,

Such a thing does not exist.

Therefore a nonempty thing

Does not exist.

20. If all this were nonempty, as in your view,

There would be no arising and ceasing.

Then the Four Noble Truths

Would become nonexistent.

21. If it is not dependently arisen,

How could suffering come to be?

Suffering has been taught to be impermanent,

And so cannot come from its own essence.

22. If something comes from its own essence,

How could it ever be arisen?

It follows that if one denies emptiness

There can be no arising [of suffering].

23. If suffering had an essence,

Its cessation would not exist.

So if an essence is posited

One denies cessation.

24. If the path had an essence,

Cultivation would not be appropriate.

If this path is indeed cultivated,

It cannot have an essence.

25. If suffering, arising, and

Ceasing are nonexistent,

If through the path suffering ceases,

In what way could one hope to attain it?

26. If through its essence

non-understanding comes to be,

In what way will understanding arise,

Is not essence stable? 
27. In this way you should understand

the activities of relinquishing and realizing and

Cultivation and the Four Fruits.

It [essence] is not appropriate.

28. For an essentialist,

Since the fruits through their essence

Are already realized

In what way could it be appropriate to cultivate them?

29. Without the fruits, there are no attainers of the fruits,

Or enterers into that stream,

From this it follows that the eight kinds of persons do not exist.

If these do not exist, there is no spiritual community.

30. From the nonexistence of the Noble Truths

Would follow the nonexistence of the True Doctrine.

If there is no Doctrine and no Community,

How could a Buddha arise?

31. Your enlightened Buddha,

Without relying on anything, would have come to be;

Your Buddha's enlightenment,

Without relying on anything, would have come to be.

32. If by means of your essence

Someone were unenlightened,

Even by practicing towards enlightenment

He could not achieve enlightenment.

33. With neither entities nor nonentities

There can be no action.

What could the nonempty do?

With an essence there is no action.

34. With neither entities nor nonentities

The fruit would arise for you.

So, for you a fruit caused by entities or nonentities

Could not arise.

35. If, for you, a fruit

Were given rise to by either entities or nonentities,

Then from entities or nonentities

How could a nonempty fruit arise?

36. If dependent arising is denied,

Emptiness itself is rejected.

This would contradict

All of the worldly conventions.

37. If emptiness itself is denied,

No action will be appropriate.

Action would not begin,

And without action there would be no agent.

Jay L. Garfield 
38. If there is essence, all of the flux

Will be unarising, unceasing,

And static. And so, the entire sphere of

Various arisen things would be nonempty.

39. If the empty does not exist,

Then action will be without profit.

The act of ending suffering and

Abandoning misery and defilement will not exist.

40. Whoever sees dependent arising

Also sees Suffering

And Misery and its arising

And the path to its cessation.

\section{NOTES}

Thanks are extended to the Venerable Lobzang Norbu Shastri and Janet Gyatso for a very thorough critical reading of and helpful critical comments on an earlier draft of this essay and of the relevant fragments of the translation, and to G. Lee Bowie and Meredith Michaels for sound suggestions regarding that draft. This essay has also benefited from the insightful questions posed by an audience at Mount Holyoke College, and from the sound suggestions of Tom Wartenberg on that occasion. My deepest appreciation goes to the Venerable Geshe Yeshes Thap-Kas for his patient and lucid teaching of this text and discussion of Nāgārjuna's position, and to the Central Institute of Higher Tibetan Studies, to its director the Venerable Professor Samdhong Rinpoche, and to my many colleagues there, including those just mentioned and the Venerable Ngawang Samden and the Venerable Ceshe Ngawang Sherab. Thanks also to my research assistant both at the Institute and at Hampshire College, Sri Yeshe Tashi Shastri, and to the Indo-American Fellowship program for grant support while I was working on these ideas.

1 - A fine point, suggested by Janet Gyatso: Though in the end, as we shall see, ultimate reality depends on our conventions in a way, it depends on our conventions in a very different way from that in which conventional reality does. Despite this difference in the structure of the relation between convention and reality in the two cases, however, it remains a distinctive feature of Nāgārjuna's system that it is impossible to speak coherently of reality independent of conventions.

2 - Some argue that there is no real difference between causes and conditions; some that a cause is one kind of condition; some that 
efficient causes are causes, and that all other causal factors contributing to an event are conditions. Some like my reading. I have found no unanimity on this interpretative question, either among Western Buddhologists or among Tibetan scholars. The canonical texts are equivocal as well. I do not argue that the distinction I here attribute to Nāgārjuna, which I defend on hermeneutical grounds, is necessarily drawn in the same way throughout the Buddhist philosophical world, or even throughout the Prāsangika-Mādhyamika literature. But it is the one Nāgārjuna draws.

3 - There are two kinds of case to be made for attributing this distinction to Nāgārjuna in this chapter. Most generally, there is the hermeneutical argument that this makes the best philosophical sense of the text. It gets Nāgārjuna drawing a distinction that is clearly suggested by his philosophical outlook and that lines up nicely with the technical terms he deploys. But we can get more textually fine-grained as well: in the first verse, Nāgārjuna explicitly rejects the existence of efficacy, and pointedly uses the word "cause." He denies that there are such things. Nowhere in chapter 1 is there a parallel denial of the existence of conditions. On the contrary, in verse 2 he positively asserts that there are four kinds of them. To be sure, this could be read as a mere partitioning of the class of effects that are described in Buddhist literature. But there are two reasons not to read it thus. First, Nāgārjuna does not couch the assertion in one of his "It might be said" locutions. Second, he never takes it back. The positive tone the text takes regarding conditions is continued in verses 4 and 5 , where Nāgārjuna asserts that conditions are conceived without efficacy in contrast with the causes rejected in 1, and where he endorses a regularist view of conditions. So it seems that Nāgārjuna does use the "cause"/"condition" distinction to mark a distinction between the kind of association he endorses as an analysis of dependent arising and one he rejects.

4 - The Venerable Lobzang Norbu Shastri has pointed out to me that this verse may not in fact be original with Nāgārjuna, but is a quotation from sutra. It appears in the Kamsika-prajñapāramitāsūtra as well as in the Mādhyamika-Śălistambasūtra. Inasmuch as these are both late texts, their chronological relation to Nāgārjuna's text is not clear.

5 - There is also a nice regress to be developed here that Nāgārjuna does not explicitly note in this chapter, though he does make use of it later in the Mülamādhyamikakārikā (chap. 7): Even if we did posit a causal power mediating between causes and their effects, we would have to explain how it is that a cause event gives rise to or acquires that power, and how the power brings about the effect. We now have two nexuses to explain, and now each one has an

Jay L. Garfield 
unobservable entity on one end. In Garfield 1990 I explore this problem in more detail and note that it is explored both by Hume and by Wittgenstein in the Tractatus.

6 - The Mādhyamika position implies that we should seek to explain regularities by reference to their embeddedness in other regularities, and so on. To ask why there are regularities at all, on such a view, would be to ask an incoherent question: the fact of explanatorily useful regularities in nature is what makes explanation and investigation possible in the first place, and is not something itself that can be explained. After all, there is only one universe, and truly singular phenomena, on such a view, are inexplicable in principle. This may connect deeply to the Buddha's insistence that questions concerning the beginning of the world are unanswerable.

7 - A formula familiar in the sutras of the Pali canon.

8 - Though this is beyond the scope of this essay, this last fact, the emptiness of the relation between the conventional world of dependently arisen phenomena and emptiness itself is of extreme importance at another stage of the Mādhyamika dialectic, and comes to salience in the Vigrahavyāvartani and in Candrakìrti's Prasannapadā. For this amounts to the emptiness of the central ontological tenet of Nāgārjuna's system, and is what allows him to claim, despite all appearances, that he is positionless. That is, Nāgārjuna thereby has a ready reply to the following apparent reductio argument (reminiscent of classical Greek and subsequent Western challenges to Pyrrhonian skepticism): You say that all things are, from the ultimate standpoint, nonexistent. That must then apply to your own thesis. It, therefore, is really nonexistent, and your words are hence only nominally true. Your own thesis, therefore, denies its own ground and is selfdefeating. This objection would be a sound one against a view that in fact asserted its own inherent existence, or grounded its truth on an inherently existing ontological basis. But, Nāgārjuna suggests here, that is not the case for his account. Rather, on his analysis, everything, including this very thesis, has only nominal truth, and nothing is either inherently existent, or true in virtue of designating an inherently existent fact.

9 - This, of course, is the key to the soteriological character of the text: reification is the root of grasping and craving, and hence of all suffering. And it is perfectly natural, despite its incoherence. By understanding emptiness Nāgārjuna intends one to break this habit and extirpate the root of suffering. But if in doing so one falls into the abyss of nihilism, nothing is achieved. For then, action itself is impossible and senseless, and one's realization amounts to nothing. Or 
again, if one relinquishes the reification of phenomena but reifies emptiness, that issues in a new grasping and craving-the grasping of emptiness and the craving for nirvāna-and a new round of suffering. Only with the simultaneous realization of the emptiness but conventional reality of phenomena and of the emptiness of emptiness, argues Nāgārjuna, can suffering be wholly uprooted.

10 - Paradox may appear to loom at this point. For, one might argue, if emptiness is empty, and if to be empty is to be merely conventional, then the emptiness of any phenomenon is a merely conventional fact. Moreover, to say that entities are merely conventional is merely conventional. Hence it would appear optional, as all conventions are, and it would further seem to be open to say that things are in fact nonconventional, and therefore nonempty. This would be a deep incoherence indeed at the heart of Nāgārjuna's system. But the paradox is merely apparent. The appearance of paradox derives from seeing "conventional" as functioning logically like a negation operator-a subtle version of the nihilistic reading Nāgārjuna is at pains to avoid, with a metalinguistic twist. For then, each iteration of "conventional" would cancel the previous occurrence, and the conventional character of the fact that things are conventional would amount to the claim that really they are not, or at least that they might not be. But in Nāgārjuna's philosophical approach, the sense of the term is more ontological than logical: to say of a phenomenon or a fact that it is conventional is to characterize its mode of subsistence. It is to say that it is without an independent nature. The fact that a phenomenon is without independent nature is, to be sure, a further phenomenon - $\mathbf{a}$ higher-order fact. But that fact, too, is without an independent nature. It, too, is merely conventional. This is another way of putting the strongly nominalistic character of Mādhyamika philosophy. So, a Platonist, for instance, might urge (and the Mādhyamika would agree) that a perceptible phenomenon is ultimately unreal. But the Platonist would assert that its properties are ultimately real. And if some Buddhist-influenced Platonist would note that among the properties of a perceptible phenomenon is its emptiness and its conventional reality, s/he would assert that these, as properties, are ultimately real. This is exactly where Nāgārjuna parts company with all forms of realism. For he gives the properties a nominalistic construal, and asserts that they, including the properties of emptiness and conventionality, are, like all phenomena, merely nominal, merely empty, and merely conventional. And so on for their emptiness and conventionality. The nominalism undercuts the negative interpretation of "conventional" and so renders the regress harmless.

Jay L. Garfield 


\section{REFERENCES}

Garfield, Jay L. 1990. "Epoche and Sūnyatā: Skepticism East and West," Philosophy East and West 40:285-307; reprinted in Clazer and Miller, eds., Words that Ring Clear as Trumpets. Amherst: Hampshire College Press, 1992.

Kalupahana, David. 1986. Nāgärjuna: The Philosophy of the Middle Way. Albany: State University of New York Press.

Philosophy East \& West 